\title{
Convalescent plasma for coronavirus disease 2019: Dose is the key
}

\author{
Jiangquan Yü ${ }^{1, *}$, Ruiqiang Zheng ${ }^{1, *}$, Haibo Qiu $^{2}$ \\ 'Department of Critical Care Medicine, Northern Jiangsu People's Hospital, Yangzhou, Jiangsu Province, China; \\ ${ }^{2}$ Department of Critical Care Medicine, Zhongda Hospital, Southeast University, Nanjing, Jiangsu Province, \\ China
}

\section{INTRODUCTION}

To develop a treatment for patients with coronavirus disease 2019 (COVID-19), researchers around the world are steadfastly exploring numerous angles, including testing of existing antiviral drugs and new compounds. One potential treatment that has garnered attention is known as convalescent plasma (CP) therapy. The approach involves giving patients an infusion of antibody-rich plasma from people who have recovered from an infection with SARS-CoV-2, the virus that causes COVID-19. Passive transfusion of $\mathrm{CP}$, in particular, has proven to be a winning and logistically feasible therapeutic strategy. ${ }^{[1]}$ There are several key questions surrounding the use of $\mathrm{CP}$ as a therapeutic. These include antibody testing and donor selection, methods of collection and storage, dose and duration of treatment, lot to lot variability, adverse effects, selection of the patients most likely to benefit, and measurement of efficacy. A number of publications have already addressed some of these issues and a few have provided either recommendations or preliminary results. ${ }^{[2-6]}$ In this review, we mainly focused on the therapeutic dose of convalescent plasma.

\section{MECHANISM OF ACTION OF CONVALESCENT PLASMA}

The use of CP relies on the concept of passive immunization where the recipients receive antibody-rich plasma from those individuals who had recovered from an illness. There are multiple proposed mechanisms by which CP acts as a therapeutic option. CP contains IgM and $\operatorname{Ig} G$ antibodies that may bind to a specific pathogen (SARS, MERS-CoV, and SARSCoV-2) and act as neutralizing antibodies and thus inhibit these viruses. ${ }^{[7]}$ First used against SARS-CoV-2 in China and Italy, CP was rapidly deployed in many countries.

\section{DOSE OF CONVALESCENT PLASMA THERAPY}

There were some positive and negative evidences of CP for COVID-19 treatment. The dose of CP can be highly variable and depends on clinical indications. Pei et al. reported successful treatment of 2 out of 3 patients with $200-500 \mathrm{ml}$ doses of CP. ${ }^{[8]}$ But no improvement in mortality despite viral clearance was reported in a retrospective observational study recruiting 6 late-stage, critically ill patients treated with 200-400 $\mathrm{mL} \mathrm{CP}$, compared to results in 13 untreated controls. ${ }^{[9]}$ Another report of five cases with COVID-19 pneumonia in Wuhan showed that a single $200-\mathrm{ml}$ dose of CP (with titers of anti-S antibodies determined by chemiluminescent immunoassay [CLIA] only) administered at a late stage led to viral clearance in two patients and radiological resolution in five patients. ${ }^{[10]}$

The limitation of those negative evidences may be dose-related, and we found that there were significant differences in $\mathrm{CP}$ titers and duration of administration, which were likely to affect the efficacy of CP therapy. So, in our opinion, the dose may be related to the titer. The required dose or volume of $\mathrm{CP}$ is primarily determined by the neutralizing antibodies' titer, estimated half-life of the antibodies and body weight of the recipient. ${ }^{[11]}$ 


\section{THE POTENTIAL EFFICIENCY OF CP DOSE ADJUDGMENT}

A Chinese pilot study (ChiCTR2000030046) of 10 critically ill patients showed that one dose of $200 \mathrm{ml}$ of CP with a neutralizing antibody titer of 1:640 resulted in an undetectable viral load in seven patients, with radiological and clinical improvement. ${ }^{[12]}$ In the first retrospective, randomized controlled trial published to date, 39 patients in New York with severe COVID-19 were transfused with 2 units of ABO-type matched $\mathrm{CP}$ with anti-Spike antibody titers of 1:320 (measured by a two-step Spike protein-directed ELISA). CP recipients were more likely than control patients to not increase their supplemental oxygen requirements by posttransfusion day 14 (odds ratio [OR], 0.86), but survival improved only for nonintubated patients (hazard ratio [HR], 0.19). ${ }^{[13]}$ Another prospective, multicenter randomized controlled trial from China (ChiCTR2000029757) enrolled 103 patients with severe to life-threatening COVID-19. CP (9-13 ml $/ \mathrm{kg}$ from donors with S-RBD [receptor binding domain] IgG titer of 1:640) was associated with a negative SARS-CoV-2 PCR test at $72 \mathrm{~h}$ in $87.2 \%$ of the CP group versus $37.5 \%$ of the BSC (best supportive care) group, but clinical improvement at 28 days was statistically different only in patients with severe, but not in life-threatening, disease. ${ }^{[14]}$

In the United States, an expanded access program (EAP) has been approved by the FDA and coordinated by Mayo Clinic, and a total of 105,717 patients were recruited, of whom 94,287 treated with CP (https:/ /www.uscovidplasma.org). Analysis of the EAP database shows a correlation of higher antibody titer in transfused CP with lower mortality, a signal that was limited to patients who did not require mechanical ventilation at the time of transfusion. In these patients, a dose-response effect emerged such that mortality was lowest in patients treated with CP containing the top 20th percentile of antibody titers, highest in patients receiving plasma with the lowest 20th percentile, and intermediate in the remaining patients. Patients not requiring mechanical ventilation with the highest antibody levels in plasma had $31 \%$ lower mortality at 30 days than those treated with low titer CP. ${ }^{[15-17]}$ Mendoza found that death was a less frequent outcome for patients that received high titer $\mathrm{CP}(>1: 1024)$ $38.6 \%$ mortality than patients that received low titer CP (1:1024) $77.8 \%$ mortality. ${ }^{[18]}$

The volume of plasma that should be administered per $\mathrm{kg}$ of body weight depends on the antibody titer. For instance, $5 \mathrm{~mL} / \mathrm{kg}$ plasma is required with an antibody titer $\geq 1: 160$. To unify a national or international preparedness program, a standardized antibody concentration is highly recommended for preparing plasma units. In previous epidemics/pandemics, e.g., Influenza H1N1, SARS, and MERS, the administration of a single dose of CP has been used, so the dose should ideally be adjusted according to the neutralization titer and/or body weight of the patient though the studies in influenza have demonstrated the complexity of pharmacokinetics and pharmacodynamic analysis of infused plasma in infected patients. ${ }^{[19]}$ Typically, one or two doses of $200 \mathrm{~mL}$ are administered (if two doses are used, they are administered at least $12 \mathrm{~h}$ apart), with infusion rates of $100-200 \mathrm{~mL} / \mathrm{h}$. The cumulative dose should be targeted according to body weight and antibody titer. ${ }^{[20]}$ Completed data on neutralizing antibody titers in COVID-19 convalescent plasma units were not available, but responders tended to have received CP units with higher antibody levels. ${ }^{[21]}$ To increase the level of protection, two or three doses of $200 \mathrm{~mL}$ plasma are recommended. ${ }^{[3]}$ Furthermore, plasma from two different donors can be used to acquire diverse fractions of antibodies that could provide a therapeutic benefit. Besides multiple doses, a single unit with a higher volume (e.g., $300 \mathrm{~mL}$ of CP) can also be administered. ${ }^{[5]}$

\section{THE CURRENT GUIDE OF CP IN THE WORLD}

The U.S. Food and Drug Administration (FDA) recommended that clinical dosing may first consider starting with one high titer COVID-19 convalescent plasma unit (about $200 \mathrm{~mL}$ ), with the administration of additional convalescent plasma units based on the prescribing physician's medical judgment and the patient's clinical response. Patients with impaired cardiac function and heart failure may require a smaller volume or more prolonged transfusion times. ${ }^{[2]}$ Recently, the American Association of Blood Banks recommended that the effectiveness of CP is related to the antibody quantity within a unit; high-titer $\mathrm{CP}$ is superior to low-titer CP. A single high-titer unit should be sufficient for most patients. ${ }^{[23]}$

\section{THE FUTURE RESEARCH OF CP}

To implement a universal recommendation, future strategies should define a uniform dose that is preferably expressed in the required neutralizing antibody titer per kilogram of body weight. In this context, it is important to determine the clinical situation of the patient in making decisions over the administration of additional units. For instance, improvements in clinical parameters, e.g., $\mathrm{O}_{2}$ saturation level, could indicate if the transfusion of more units is needed. ${ }^{[2]}$ The optimal dose for CP therapy still requires large, high-quality studies to provide data.

\section{CONCLUSIONS}


CP manufacturing should be considered among the first responses during a pandemic. Despite huge controversy in the current researches from small trials, multicenter randomized controlled trials should be encouraged in order to establish efficacy and provide hints about the most effective schedule. In our opinion, the dose including the antibody titer and the weight of patients maybe is the key.

\section{Source of Funding}

Yangzhou social development project (YZ2018075), Yangzhou Medical Talent (ZDRC201845), Top-notch Talents of "Six-one Projects" of Jiangsu Commission of Health (LGY2019036), and Jiangsu Province "333 Projects" (BRA2020183).

\section{Conflict of Interest}

None declared.

\section{REFERENCES}

1. Mair-Jenkins J, Saavedra-Campos M, Baillie JK, Cleary P, Khaw F M, Lim WS, et al. The effectiveness of convalescent plasma and hyperimmune immunoglobulin for the treatment of severe acute respiratory infections of viral etiology: a systematic review and exploratory meta-analysis. J Infect Dis 2015; 211: 80-90.

2. Cao H, Shi Y. Convalescent plasma: possible therapy for novel coronavirus disease 2019. Transfusion 2020; 60: 1078-83.

3. Epstein J, Burnouf T. Points to consider in the preparation and transfusion of COVID-19 convalescent plasma. Vox Sang 2020; 115: 485-7.

4. Bloch EM, Shoham S, Casadevall A,Sachais, BS, Shaz B, Winters JL, et al. Deployment of convalescent plasma for the prevention and treatment of COVID-19. J Clin Invest 2020; 130: 2757-65.

5. Salazar E, Christensen PA, Graviss EA, Nguyen DT, Castillo B, Chen J, et al. Treatment of Coronavirus Disease 2019 (COVID-19) Patients with Convalescent Plasma. Am J Pathol 2020; 190: 1680-90.

6. Valk SJ, Piechotta V, Chai KL, Doree C, Monsef I, Wood EM, et al. Convalescent plasma or hyperimmune immunoglobulin for people with COVID-19: a rapid review. Cochrane Database Syst Rev 2020; 5 : CD013600.

7. van Griensven J, Edwards T, de Lamballerie X, Semple MG, Gallian P, Baize, S.et al. Evaluation of Convalescent Plasma for Ebola Virus Disease in Guinea. N Engl J Med 2016; 374: 33-42.

8. Pei S, Yuan X, Zhang Z, Yao R, Xie Y, Shen M, et al. Convalescent Plasma to Treat COVID-19: Chinese Strategy and Experiences. Available from: https: //doi.org/10.1101/2020.04.07.20056440. Accessed on Apr. 11, 2020.

9. Zeng QL, Yu ZJ, Gou JJ, Li GM, Ma SH, Zhang GF, et al. Effect of
Convalescent Plasma Therapy on Viral Shedding and Survival in Patients With Coronavirus Disease 2019. J Infect Dis 2020; 222: 38-43.

10. Shen C, Wang Z, Zhao F, Yang Y, Li J, Yuan J, et al. Treatment of 5 Critically Ill Patients With COVID-19 With Convalescent Plasma. JAMA 2020; 323: 1582-9.

11. Cheng Y, Wong R, Soo YO, Wong WS, Lee CK, Ng MH, et al. Use of convalescent plasma therapy in SARS patients in Hong Kong. Eur J Clin Microbiol Infect Dis 2005; 24: 44-6.

12. Duan K, Liu B, Li C, Zhang H, Yu T, Qu J, et al. Effectiveness of convalescent plasma therapy in severe COVID-19 patients. Proc Natl Acad Sci U S A, 2020; 117: 9490-6.

13. Liu STH, Lin HM, Baine I, Wajnberg A, Gumprecht JP, Rahman F, et al. Convalescent plasma treatment of severe COVID-19: A matched control study. Nat Med 2020; 26: 1708-13.

14. Ye M, Fu D, Ren Y, Wang F, Wang D, Zhang F, Xia X, et al. Treatment with convalescent plasma for COVID-19 patients in Wuhan, China. J Med Virol 2020; 92: 1890-901.

15. Li L, Zhang W, Hu Y, Tong X, Zheng S, Yang J, et al. Effect of Convalescent Plasma Therapy on Time to Clinical Improvement in Patients With Severe and Life-threatening COVID-19: A Randomized Clinical Trial. JAMA 2020; 324: 460-70.

16. Liu STH, Lin HM, Baine I, Wajnberg A, Gumprecht JP, Rahman F, et al. Convalescent plasma treatment of severe COVID-19: a propensity score-matched control study. Nat Med 2020; 26: 1708-13.

17. Salazar E, Perez, KK, Ashraf M, Chen J, Castillo B, Christensen PA, et al. Treatment of Coronavirus Disease 2019 Patients with Convalescent Plasma Reveals a Signal of Significantly Decreased Mortality. Am J Pathol 2020; 190: 2290-303.

18. Mendoza RP, Fyke William, Daniel D, Gabutan E, Das B, Bajaj H, et al. Administration of high titer convalescent anti-SARS-CoV-2 plasma: From donor selection to monitoring recipient outcomes. Hum Immunol 2021; 82: 255-63.

19. Hung IF, To KK, Lee CK, Lee KL, Chan K, Yan WW, et al. Convalescent plasma treatment reduced mortality in patients with severe pandemic influenza A (H1N1) 2009 virus infection. Clin Infect Dis 2011; 52: 44756.

20. Knudson CM, Jackson JB. COVID-19 convalescent plasma: phase 2. Transfusion 2020; 60: 1332-3.

21. Joyner MJ, Carter RE, Senefeld JW, Klassen SA, Mills JR, Johnson PW, et al. Convalescent Plasma Antibody Levels and the Risk of Death from Covid-19. N Engl J Med, 2021; 384: 1015-27.

22. U.S. Food \& Drug Adminstration, Emergency Use Authorization (EUA) of COVID-19 Convalescent Plasma for Treatment of Hospitalized Patients with COVID-19, [ER/OL]. Available at: https://www.fda.gov/ media/141478/download,2021-2-4. Access on April 27, 2021.

23. Cohn CS, Estcourt L, Grossman BJ, Pagano MB, Allen ES, Bloch EM, et al. COVID-19 convalescentplasma: Interim recommendations from the AABB. Transfusion 2021; 61:1313-23.

24. Perotti C, Del Fante C, Baldanti F, Franchini M, Percivalle E, Vecchio Nepita E, et al. Plasma from donors recovered from the new Coronavirus 2019 as therapy for critical patients with COVID-19 (COVID-19 plasma study): a multicentre study protocol. Intern Emerg Med 2020; 15: 819-24.

How to cite this article: Yu J, Zheng R, Qiu H. Convalescent plasma for coronavirus disease 2019: Dose is the key. J TransI Intern Med 2021; 9: 68-70. 